\title{
Improved Electrical Performances of An InP/ InGaAs Heterojunction Bipolar Transistor
}

\author{
Jihane Ouchrif, Abdennaceur Baghdad, Aicha Sahel, \\ Abdelmajid Badri, Abdelhakim Ballouk \\ Electrical Engineering Department, EEA\&TI Laboratory, Faculty of Sciences and Techniques of Mohammedia/ \\ Hassan II University of Casablanca, Morocco [E-mail: ouchrif.jihane1@gmail.com]
}

\begin{abstract}
Bipolar Heterojunction Transistors (HBTs) have proved to be excellent devices for applications in microwave telecommunication systems. In this study, the aim is to optimize and to improve the InP / InGaAs HBT electrical performances. For this, we used the software TCAD-Silvaco (Technology Computer-Aided Design) which allows the simulation of the electrical and physical behavior of electronic components. We worked with the interactive tool DeckBuild to define the simulation program, and we used the device structure editor DevEDIT to design the InP/InGaAs HBT according to its technological characteristics (dimension, doping, meshing ...), and also the device simulator ATLAS which enables the electrical characterization of the semiconductor component HBT. Afterwards, we defined an appropriate topology taking into account physical models among them we cite SRH, BGN..., then we investigated the impact of the base width and the emitter length of the InP/ InGaAs HBT on its electrical performances and in particular in terms of the HBT characteristic parameters, such as the static current gain. Consequently, the results obtained allowed us to define an optimal structure of the component adapted for very high frequency applications in the microwave domain.
\end{abstract}

Keywords: ATLAS, DECKBUILD, HBT, Microwave, TCAD, Telecommunication

\section{Introduction}

Nowadays, the development of communication and information technologies requires high-speed semiconductor components and with low noise level. III-V semiconductor materials are remarkable by their electronic transport properties, as they exhibit high electronic mobility and a direct band gap. Moreover, in the electronic devices manufacturing, III-V semiconductor materials have been extensively used due to their speed excellent characteristics which enable the operation of these electronic devices at very high frequencies [1].

In this perspective, Heterojunction Bipolar Transistors (HBTs) based on semiconductor materials InP and InGaAs are performing and promising candidates for microwave and high speed applications [2] [3].The performance of the high frequency and the high speed of the Heterojunction Bipolar Transistors based on InP is mainly due to the low width of the bandgap of InGaAs used in the base layer, which possesses a great mobility of electrons, who results from the very short transit times for the electrons crossing the base [3][4].

In this work, the principal objective is to enhance the electrical performances in terms of the static current gain of the Heterojunction Bipolar Transistor (HBT) composed of an InP binary alloy and an InGaAs ternary alloy. For the HBT manufacturing, the growth of the epitaxial layers is carried out using the Molecular Jet Epitaxy (MBE) technique on a semi-insulating InP substrate using a source of GaP decomposition [5].

\section{Device Description}

\section{HBT Modeling}

The InP/InGaAs HBT used in this study is a single Heterojunction Bipolar Transistor, our work is mainly based on the papers [3] [6] for the reference device structure of the semiconductor component HBT. The emitter surface of the InP/InGaAs HBT is equal to $5 \times 5 \mu \mathrm{m}^{2}$, The table $\mathrm{n}^{\circ} \mathrm{I}$ illustrates the various epitaxial layers composing this device, and also the different semiconductor materials for each layer, the dopings and the thicknesses. In order to design it, we used the device structure editor DevEDIT [7], and we obtained the simulated device shown in Figure 1.

\begin{tabular}{|c|c|c|c|}
\hline Layer & Material & Doping $\left(\mathbf{c m}^{-3}\right)$ & Thickness (nm) \\
\hline Cap & $\mathrm{In}_{0.47} \mathrm{Ga}_{0.53} \mathrm{As}$ & $\mathrm{n}=1 \times 10^{19}$ & 135 \\
\hline Emitter 1 & $\mathrm{In}_{0.47} \mathrm{Ga}_{0.53} \mathrm{As}$ & $\mathrm{n}=1 \times 10^{17}$ & 135 \\
\hline Emitter 2 & $\mathrm{InP}$ & $\mathrm{n}=1 \times 10^{17}$ & 40 \\
\hline Spacer & $\mathrm{In}_{0.47} \mathrm{Ga}_{0.53} \mathrm{As}$ & - & 5 \\
\hline Base & $\mathrm{In}_{0.47} \mathrm{Ga}_{0.53} \mathrm{As}$ & $\mathrm{p}=1.5 \times 10^{19}$ & 65 \\
\hline
\end{tabular}




\begin{tabular}{|c|c|c|c|}
\hline Collector & $\mathrm{In}_{0.47} \mathrm{Ga}_{0.53} \mathrm{As}$ & $\mathrm{n}=1 \times 10^{16}$ & 630 \\
\hline Sub-collector & $\mathrm{In}_{0.47} \mathrm{Ga}_{0.53} \mathrm{As}$ & $\mathrm{n}=1 \times 10^{19}$ & 500 \\
\hline Buffer & $\mathrm{In}_{0.47} \mathrm{Ga}_{0.53} \mathrm{As}$ & - & 10 \\
\hline Substrate & \multicolumn{2}{|c|}{ Semi-insulating InP } \\
\hline
\end{tabular}

Table I. Layer Structure of InP/InGaAs HBT

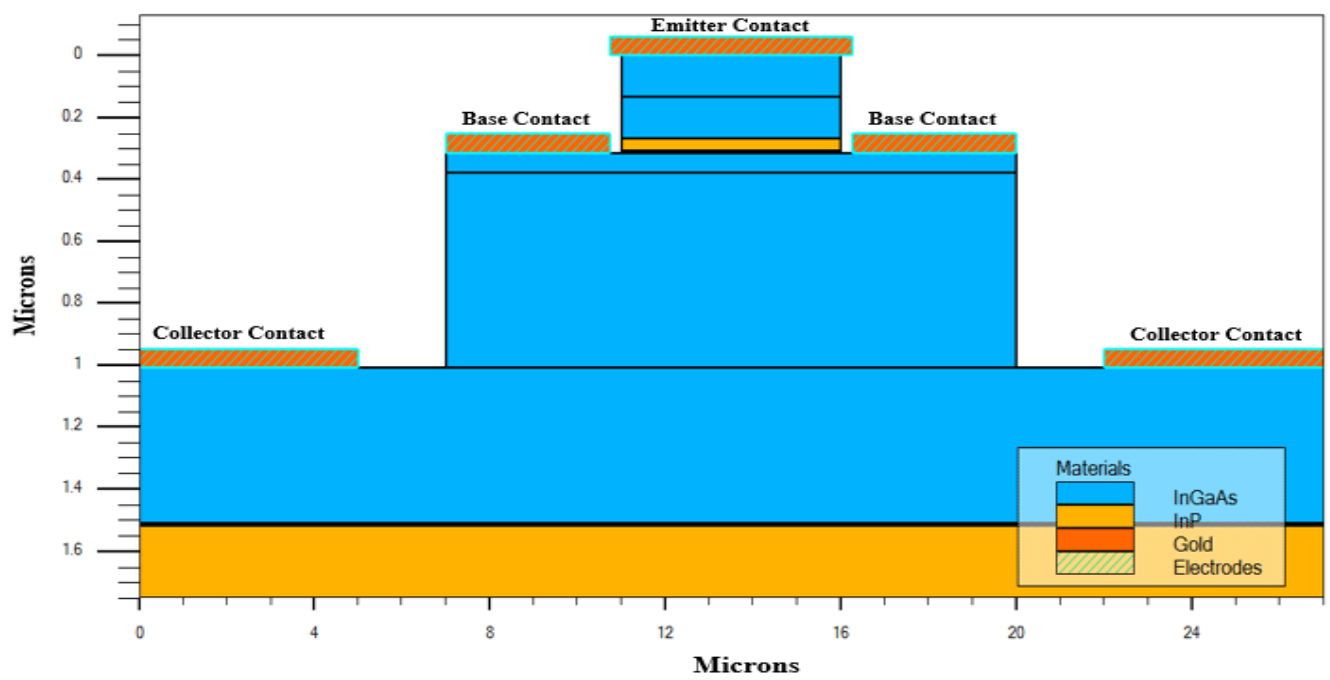

Fig. 1. Simulated Device Structure of the $\mathrm{InP} / \mathrm{InGaAs} \mathrm{HBT}$

\section{Material Parameters and Physical Models}

In order to simulate the electrical characteristics, material parameters must be defined by the user. However, the ATLAS database does not integrate III-V semiconductor materials, therefore we based our work on the papers [6] [8] [9] for the parameters values cited in Table $\mathrm{n}^{\circ} \mathrm{II}$ and $\mathrm{n}^{\circ} \mathrm{III}$.

\begin{tabular}{|c|c|c|c|c|}
\hline Parameter & Symbol & Unit & InP & In $_{\mathbf{0 . 4 7}} \mathbf{G a}_{\mathbf{0 . 5 3}} \mathbf{A s}$ \\
\hline Permittivity & $\varepsilon_{\mathrm{r}} / \varepsilon_{\mathrm{o}}$ & - & 12.35 & 13.88 \\
\hline Energy Gap & $\mathrm{E}_{\mathrm{g}}$ & $\mathrm{eV}$ & 1.35 & 0.75 \\
\hline Electron Affinity & $\chi$ & $\mathrm{eV}$ & 4.38 & 4.6 \\
\hline Electron Effective Mass & $\mathrm{m}^{*}{ }_{\mathrm{n}} / \mathrm{m}_{\mathrm{o}}$ & - & 0.08 & 0.041 \\
\hline Hole Effective Mass & $\mathrm{m}^{*}{ }_{\mathrm{p}} / \mathrm{m}_{\mathrm{o}}$ & - & 0.50 & 0.47 \\
\hline Effective density of states in the conduction band & $\mathrm{N}_{\mathrm{c}}$ & $\mathrm{cm}^{-3}$ & $6.4 \times 10^{17}$ & $8.9 \times 10^{16}$ \\
\hline Effective density of states in the valence band & $\mathrm{N}_{\mathrm{v}}$ & $\mathrm{cm}^{-3}$ & $1 \times 10^{19}$ & $1 \times 10^{18}$ \\
\hline Electron Saturation Velocity & $\mathrm{V}_{\mathrm{sat}}$ & $\mathrm{cm}_{\mathrm{s}} \mathrm{s}^{-1}$ & $2.6 \times 10^{7}$ & $2.5 \times 10^{7}$ \\
\hline Hole Saturation Velocity & $\mathrm{V}_{\text {sat }}$ & $\mathrm{cm}^{-1}$ & $6.6 \times 10^{6}$ & $4.9 \times 10^{6}$ \\
\hline
\end{tabular}

Table II. InP/InGaAs HBT Material Parameters

In the simulation program of the HBT semiconductor component, we added the concentrationdependent analytical mobility referring to the Caughey and Thomas mobility model in order to consider the doping effect on electron and hole mobility in the semiconductor material. The known formula of the effective mobility of electrons and holes in each region is defined by the equation suggested by Caughey - Thomas [6] [10]:

Where,

$$
\mu=\mu_{\min }\left(\frac{T_{L}}{300}\right)^{\beta}+\frac{\mu_{\max }\left(\frac{T_{L}}{300}\right)^{\delta}-\mu_{\min }\left(\frac{T_{L}}{300}\right)^{\beta}}{1+\left(\frac{T_{L}}{300}\right)^{\gamma}\left(\frac{N}{N_{C}}\right)^{\alpha}}
$$

$\beta, \delta$ and $\gamma$ are the temperature dependent coefficients, $T_{L}=300 \mathrm{~K}$. 
Improved Electrical Performances of An InP/InGaAs Heterojunction Bipolar Transistor

\begin{tabular}{|c|c|c|c|}
\hline \multicolumn{5}{|c|}{ Electron } \\
\hline Parameter & Units & InP & $\mathbf{I n}_{\mathbf{0 . 4 7}} \mathbf{G a}_{\mathbf{0 . 5 3}} \mathbf{A s}$ \\
\hline $\boldsymbol{\mu}_{\max }$ & $\mathrm{cm}^{2} \cdot \mathrm{V}^{-1} \cdot \mathrm{sec}^{-1}$ & 4917 & 11599 \\
\hline $\boldsymbol{\mu}_{\min }$ & $\mathrm{cm}^{2} \cdot \mathrm{V}^{-1} \cdot \mathrm{sec}^{-1}$ & 300 & 3372 \\
\hline $\mathbf{N}_{\mathbf{c}}$ & $\mathrm{cm}^{-3}$ & $6.4 \times 10^{17}$ & $8.9 \times 10^{16}$ \\
\hline $\boldsymbol{\alpha}$ & - & 0.46 & 0.76 \\
\hline \multicolumn{4}{|c|}{ Hole } \\
\hline Parameter & Units & $\mathbf{I n P}$ & $\mathbf{I n}_{\mathbf{0 . 4 7}} \mathbf{G a}_{\mathbf{0} .53} \mathbf{A s}$ \\
\hline $\boldsymbol{\mu}_{\max }$ & $\mathrm{cm}^{2} \cdot \mathrm{V}^{-1} \cdot \mathrm{sec}^{-1}$ & 151 & 331 \\
\hline $\boldsymbol{\mu}_{\min }$ & $\mathrm{cm}^{2} \cdot \mathrm{V}^{-1} \cdot \mathrm{sec}^{-1}$ & 20 & 75 \\
\hline $\mathbf{N}_{\mathbf{v}}$ & $\mathrm{cm}^{-3}$ & $1 \times 10^{17}$ & $1 \times 10^{18}$ \\
\hline $\boldsymbol{\alpha}$ & - & 0.96 & 1.37 \\
\hline
\end{tabular}

Table III. Summary of mobility model parameters for materials InP and $\operatorname{In}_{0.47} \mathrm{Ga}_{0.53} \mathrm{As}$

Table $n^{\circ}$ III represents the parameters which were used to define the mobility of electrons and holes. $\mu_{\max }$ and $\mu_{\min }$ are the maximum and minimum mobilities at low and high levels of doping.

The physical models [11] included in the TCAD-SILVACO software were added in the simulation. Among the integrated models, we cite the carrier statistical model (BGN), the recombination model (SRH), the Selberherr's model of the impact of ionization (IMPACT SELB), the Tunnel effect model (BBT.STD), and the Optical model of recombination (OPTR).

$\checkmark$ BGN Model (Bandgap Narrowing) [11] : it is a carrier statistic model, and it is essential in heavily doped regions, and crucial for bipolar gain.

$\checkmark$ SRH Model (Schockley-Read-Hall) [11] : it is an imperative recombination model that uses the fixed lifetime of the minority carriers.

$\checkmark$ Selberherr's Model (IMPACT SELB) [11] : it is a significant model of impact ionization, the parameters depending on the temperature are included with it.This model is used and recommended for the most cases.

$\checkmark$ Band-to-band Model (BBT.STD) [11] : it is a tunneling model used for direct transitions. It is actually required with very high fields.

$\checkmark$ OPTR Model (Optical model) [11] : it is a band-band recombination model, and it is mainly used for direct materials.

\section{Static Current Gain of HBT}

The static current gain of the HBT is expressed in the following way [12]:

Where,

$$
\beta \propto \frac{D_{\mathrm{nB}}}{D_{\mathrm{pE}}} \frac{L_{\mathrm{pE}}}{\mathrm{W}_{\mathrm{B}}} \frac{\mathrm{N}_{\mathrm{CB}}}{\mathrm{N}_{\mathrm{CE}}} \frac{\mathrm{N}_{\mathrm{VB}}}{\mathrm{N}_{\mathrm{VE}}} \frac{\mathrm{N}_{\mathrm{D}}}{\mathrm{N}_{\mathrm{A}}} \exp \left(\frac{\Delta \mathrm{E}_{\mathrm{g}}}{\mathrm{KT}}\right)
$$

- $\mathrm{D}_{\mathrm{nB}}$ is the diffusion coefficient for electrons in the base, and $\mathrm{D}_{\mathrm{pE}}$ is the diffusion coefficient for holes in the emitter,

- $\mathrm{L}_{\mathrm{pE}}$ is the diffusion length for holes in the emitter, and $\mathrm{W}_{\mathrm{B}}$ is the base width,

- $\mathrm{N}_{\mathrm{CB}}$ and $\mathrm{N}_{\mathrm{CE}}$ represent the conduction band density of states respectively for the base and emitter materials,

- $\mathrm{N}_{\mathrm{VB}}$ and $\mathrm{N}_{\mathrm{VE}}$ represent the valence band density of states respectively for the base and emitter materials,

$-\mathrm{N}_{\mathrm{D}}$ and $\mathrm{N}_{\mathrm{A}}$ are the doping concentrations for the emitter and the base,

$-\Delta \mathrm{E}_{\mathrm{g}}$ is the energy bandgap difference of the emitter and the base materials,

- $\mathrm{K}$ is the Boltzmann constant,

- $\mathrm{T}$ is the Temperature in Kelvin $(\mathrm{K})$.

\section{Results And Discussions}

The figures below illustrate the simulation results using the software TCAD-Silvaco. We carried out a physical and numerical modeling of the $\mathrm{InP} / \mathrm{InGaAs} \mathrm{HBT}$. This modeling allows to solve numerically the equations of the carriers and the equations of the electric fields in each of the HBT layers, the numerical method used in this work is the newton method. Then, we investigated the impact of the base width and the emitter length on the static current gain of the InP/InGaAs HBT. 


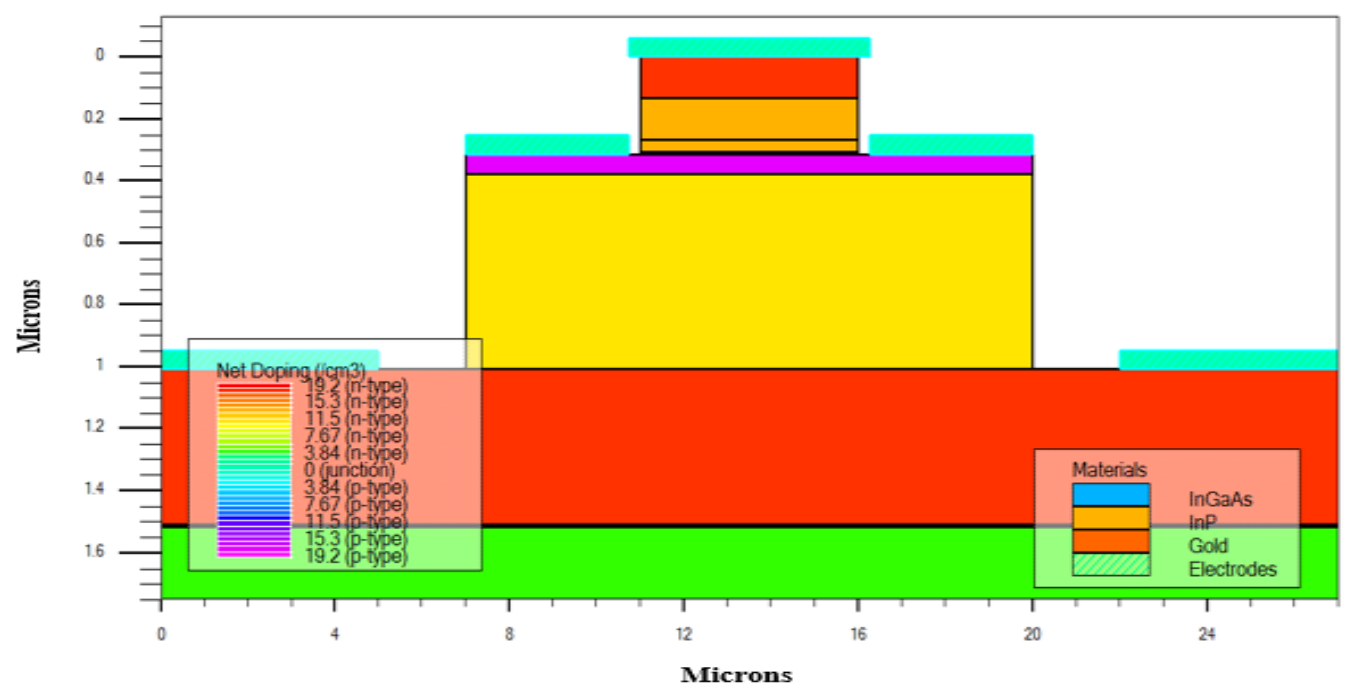

Fig. 2. HBT layers dopings

Figure 2 shows the different dopings for each layer of the InP/InGaAs HBT, it is clear that the option of the net doping enables to show the $\mathrm{n}$-doped and p-doped regions as well as the diffusions of the dopings for the intrinsic layers, such as the spacer layer which is under the influence of the diffusion of the p-doped base region.

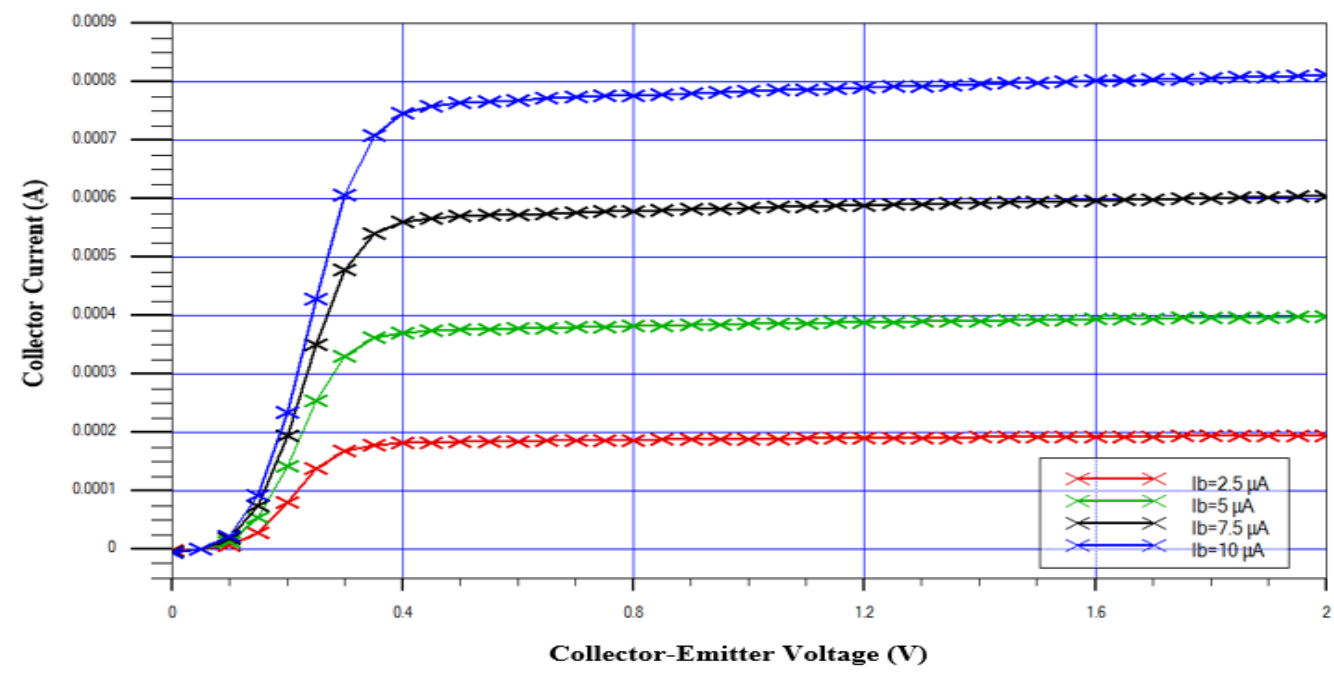

Fig. 3. Simulated Ic -Vce Characteristics for the InP/InGaAs HBT

Figure 3 shows the simulation result of the output characteristics Ic - Vce of the Heterojunction Bipolar Transistor (HBT). For each value of $I_{b}=2.5 \mu \mathrm{A}, 5 \mu \mathrm{A}, 7.5 \mu \mathrm{A}$ and $10 \mu \mathrm{A}$, we plotted the function $\mathrm{I}_{\mathrm{c}}=\mathrm{f}\left(\mathrm{V}_{\mathrm{ce}}\right)$. We observed that for a voltage $V_{c e}$ which varies from 0 to $2 \mathrm{~V}$, there is an offset in turn-on voltage (Vceo) which is equal to $50 \mathrm{mV}$, this is due to the difference between the voltages of the base-emitter diode (heterojunction) and the base-collector diode (homojunction), this result is different from what is usually observed on silicon bipolar transistors. According to the Figure 3, InP/InGaAs HBT has a static current gain of about 79.01.

For the purpose of defining an appropriate device HBT that can be used for microwave applications, we investigated optimum technological parameters which allow to obtain the maximum static current gain, for this we performed several simulations in the aim to determine the influences of different parameters, such as the base width and the emitter length on the static current gain of the device. We have worked with the reference structure parameters listed in Table $n^{\circ} I$. 


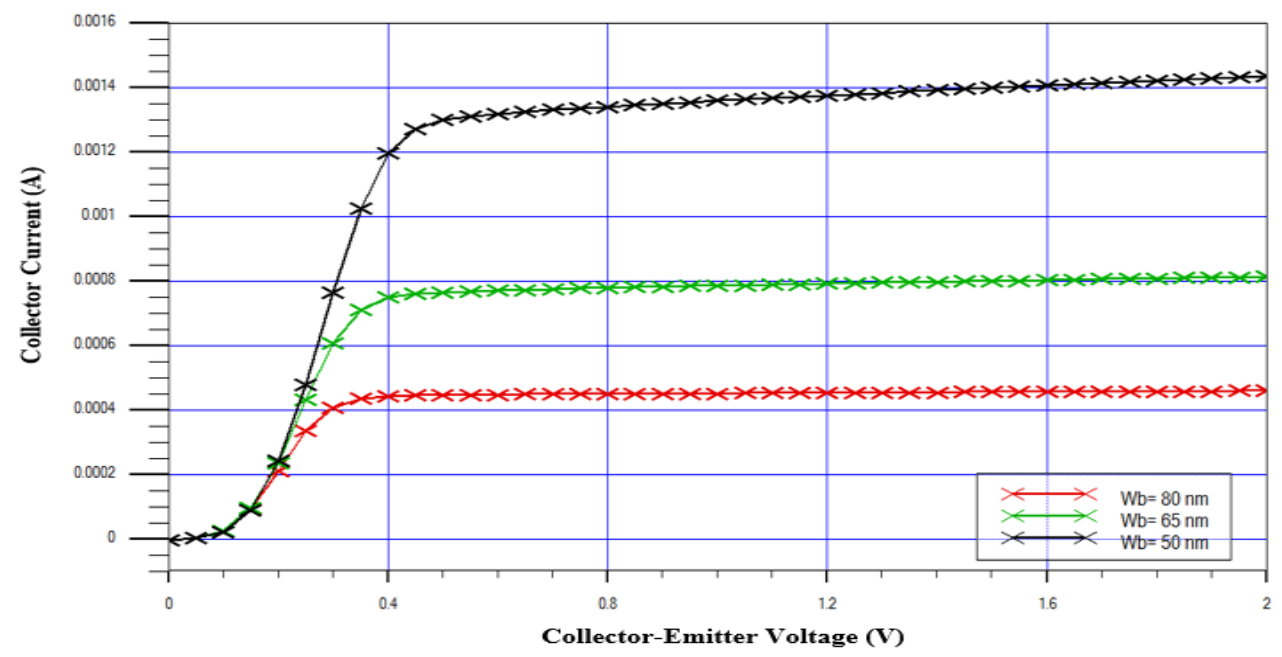

Fig. 4. Simulated Ic -Vce Characteristics for the $I n P / I n G a A s ~ H B T$ at a constant current $I_{b}=10 \mu A$ for different base widths

\begin{tabular}{|c|c|c|c|}
\hline Base width $(\mathbf{n m})$ & $\mathbf{I}_{\mathbf{b}}(\boldsymbol{\mu} \mathbf{A})$ & $\mathbf{I}_{\mathbf{c}}(\mathbf{m A})$ & Current gain $\boldsymbol{\beta}$ \\
\hline 50 & 10 & 0.13742 & 137.42 \\
\hline 65 & 10 & 0.7901 & 79.01 \\
\hline 80 & 10 & 0.4516 & 45.16 \\
\hline
\end{tabular}

Table IV. Influence of the base width on the output parameters of InP/InGaAs HBT at $\mathrm{I}_{b}=10 \mu \mathrm{A}$

According to Figure 4 and Table $\mathrm{n}^{\circ} \mathrm{IV}$, it is remarkable that for a current base $\mathrm{I}_{\mathrm{b}}$ set at $10 \mu \mathrm{A}$, the static current gain generally increases with the decrease in the base width. As a result, it is the thinnest base width that is equal to $50 \mathrm{~nm}$ which gives the highest static current gain of about 137.42. We noticed a net improvement compared to the current gain obtained with the reference structure of value equal to 79.01. Accordingly, it is an improvement of about $73.92 \%$.

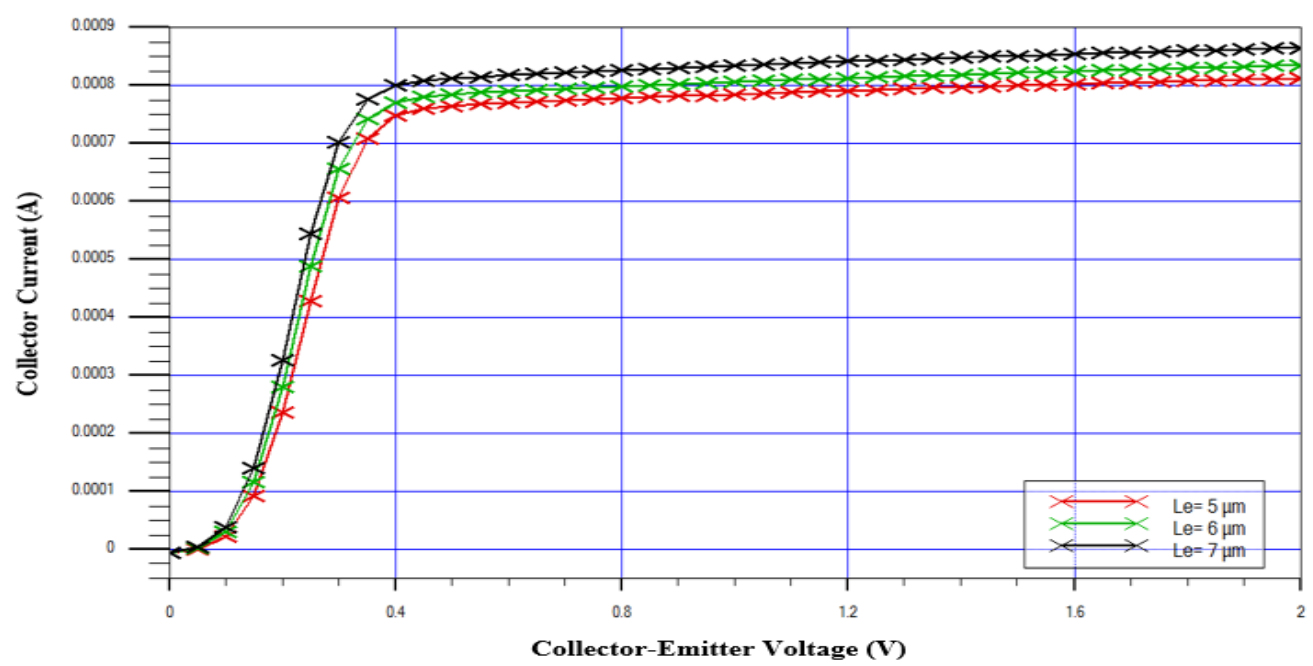

Fig. 5. Simulated Ic -Vce Characteristics for the InP/InGaAs HBT at a constant current $I_{b}=10 \mu A$ for different emitter lengths

\begin{tabular}{|c|c|c|c|}
\hline Emitter length $(\boldsymbol{\mu m})$ & $\mathbf{I}_{\mathbf{b}}(\boldsymbol{\mu} \mathbf{A})$ & $\mathbf{I}_{\mathbf{c}}(\mathbf{m A})$ & Current gain $\boldsymbol{\beta}$ \\
\hline 5 & 10 & 0.7901 & 79.01 \\
\hline 6 & 10 & 0.8116 & 81.16 \\
\hline 7 & 10 & 0.8404 & 84.04 \\
\hline
\end{tabular}

Table V. Influence of the emitter length on the output parameters of InP/InGaAs HBT at $\mathrm{I}_{\mathrm{b}}=10 \mu \mathrm{A}$

Based on Figure 5 and Data presented in Table $n^{\circ} \mathrm{V}$ for a current base $\mathrm{I}_{\mathrm{b}}$ fixed at $10 \mu \mathrm{A}$, when we increase the emitter length, the static current gain increases. Therefore, it is the biggest emitter length that is chosen equal to $7 \mu \mathrm{m}$ which gives the highest current gain of value equal to 84.04 . Then, there is a net 
improvement compared to the current gain obtained with the reference structure which is 79.01 . The estimated improvement is about $6.36 \%$.

After carrying out the physical and numerical modeling of the new improved structure, and considering the optimized technological parameters, in particular the base width equal to $50 \mathrm{~nm}$ and the emitter length equal to $7 \mu \mathrm{m}$, we obtained a static current gain better than that of the reference structure.

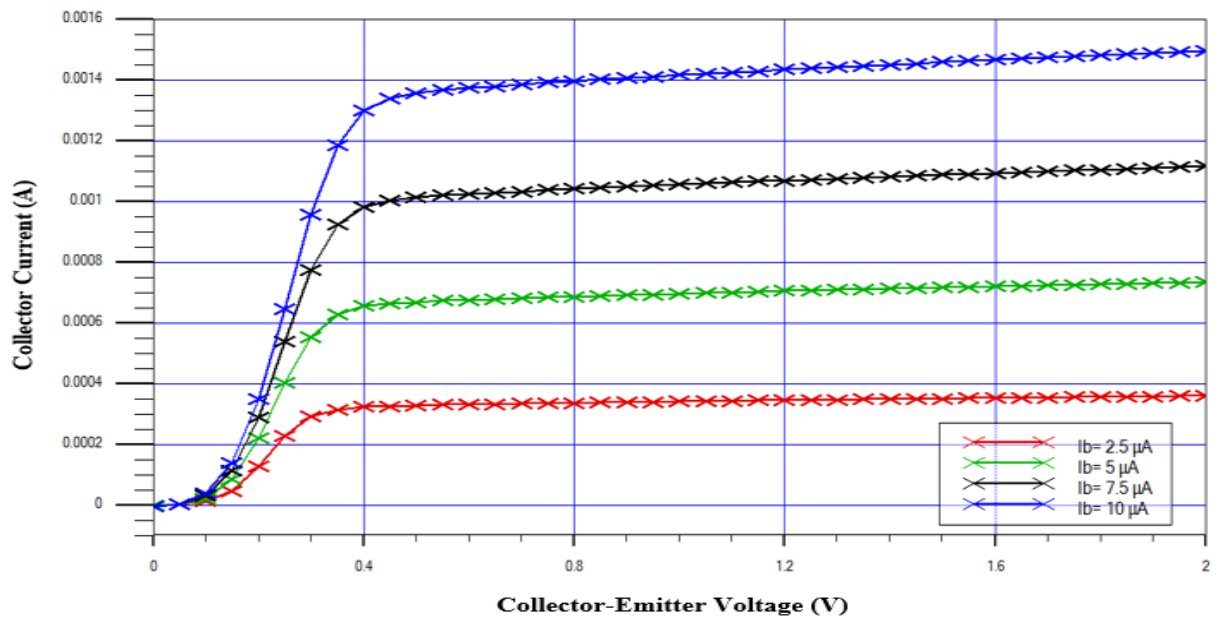

Fig. 6. Simulated Ic -Vce Characteristics for the improved InP/InGaAs HBT

Figure 6 shows the simulated output characteristics $I_{c}=f\left(V_{c e}\right)$ for the improved electronic device InP/InGaAs HBT. For each value of $\mathrm{I}_{\mathrm{b}}=2.5 \mu \mathrm{A}, 5 \mu \mathrm{A}, 7.5 \mu \mathrm{A}$ and $10 \mu \mathrm{A}$, the function $\mathrm{I}_{\mathrm{c}}=\mathrm{f}\left(\mathrm{V}_{\mathrm{ce}}\right)$ was plotted. We then observed that for a voltage $V_{c e}$ which varies from 0 to $2 \mathrm{~V}$, there is an offset in turn-on voltage (Vceo) which is equal to $50 \mathrm{mV}$. Therefore, the static current gain estimated in this case is of the order of 143.29. Consequently, for $\mathrm{I}_{\mathrm{b}}=10 \mu \mathrm{A}$ we found that the improvement is about $81.35 \%$.

\section{Conclusion}

In this paper, we have modeled the structure of the npn Heterojunction Bipolar Transistor (HBT) using the TCAD-Silvaco software. To better take into account the physical mechanisms, we have integrated the physical models such as SRH, BGN... in our simulations. Then, we investigated the impact of the base width and the emitter length on the static current gain. As a result, we found that for a base width equal to $50 \mathrm{~nm}$ and an emitter length equal to $7 \mu \mathrm{m}$, we have observed a net improvement in the static current gain, which increases from 79.01 for the reference structure to 143.29 for the improved structure. Finally, the net improvement is about $81.35 \%$. For our perspectives, we propose to investigate the influence of the epitaxial layers dopings on the static current gain, and we propose to extend the study to a modification in the HBT topology in order to have a static current gain as high as possible.

\section{References}

[1] T Gonzalez Sanchez,J E Velazquez Pérez,P M Gutiérrez Conde and D Pardo Collantes, "Electron transport in InP under high electric field conditions", IOP science, pp.31-36,1992.

[2] C. H. Li, H. L. Lu, Y. M. Zhang, M. Liu, and X. H. Zhao, "Proton-Induced Degradation of InP/InGaAs HBTs Predicted by Nonionizing Energy Loss Model”, IEEE TRANSACTIONS ON NUCLEAR SCIENCE, VOL. 62, NO. 3, pp.1336-1340, JUNE 2015.

[3] J.Sexton and M.Missous, "ANNEALING EXPERIMENTS ON INP/INGAAS SINGLE AND DOUBLE HBTs GROWN BY MOLECULAR BEAM EPITAXY", in Electron Devices for Microwave and Optoelectronic Applications, 2002.EDMO 2002.The $10^{\text {th }}$ IEEE International Symposium on, 2002, pp.300-305.

[4] Subhra Chowdhury and Sukla Basu, "Analytical Modelling of Base Transit Time and Early Voltage of InP/InGaAs Heterojunction Bipolar Transistor for Nonuniform Base Doping Profile", Proceeding of the 2011 IEEE Students' Technology Symposium, IIT Kharagpur, 14-16 January 2011.

[5] M.Missous, "Optical and electrical properties of $\operatorname{In}_{0.48}\left(\mathrm{Al}_{\mathrm{x}} \mathrm{Ga}_{(1-\mathrm{x})}\right)_{0.52} \mathrm{P}$ grown by Solid Source MBE using a GaP Decomposition source'”.EDMO 2001 (Cat.No.01TH8567).IEEE.2001, pp.1-8.

[6] T. Tauqeer, J. Sexton, F. Amir and M. Missous, "Two-Dimensional Physical and Numerical Modelling of InP-based Heterojunction Bipolar Transistors ", The $7^{\text {th }}$ International Conference on Advanced Semiconductor Devices and Microsystems, pp.271-274, 12-16 Oct 2008.

[7] DevEdit User's Manual, SILVACO INTERNATIONAL, 2006.

[8] Suman Datta,Shen Shi,Kenneth P.Roenker,Marc M.Cahay,and William E.Stanchina, "Simulation and Design of InAlAs/InGaAs pnp Heterojunction Bipolar Transistors", IEEE TRANSACTIONS ON ELECTRON DEVICES,VOL.45,NO.8,pp.16341643 ,AUGUST 1998 
[9] Joseph W.Parks,Arlynn W.Smith,Kevin F.Brennan, and Larry E.Tarof,"Theoretical Study of Device Sensitivity and Gain Saturation of separate Absorption,Grading, Charge,and Multiplication InP/InGaAs Avalanche Photodiodes", IEEE Transactions on Electron Devices, Vol.43,No.12,pp.2113-2121, December 1996.

[10] Caughey DM,Thomas R E.Proc IEEE;52;2192; 1967

[11] ATLAS User's Manual, DEVICE SIMULATION SOFTWARE, SILVACO INTERNATIONAL, September 3, 2010.

[12] Jean-Christophe MARTIN, "Study of the degradation mechanisms of heterojunction bipolar transistors on InP substrate for optical communications", University of Bordeaux 1, Ph.D Thesis, 2004.

Jihane Ouchrif. "Improved Electrical Performances of An InP/ InGaAs Heterojunction Bipolar Transistor." IOSR Journal of Electrical and Electronics Engineering (IOSR-JEEE) 12.3 (2017): 53-59. 